\title{
Implication of Reduced Herbicide Rates on Resistance Enrichment in Wild Oat (Avena fatua)
}

\author{
H. J. Beckie and K. J. Kirkland
}

Saskatoon Research Centre, Agriculture and Agri-Food Canada, Saskatoon, SK, S7N 0X2

Key words: Avena fatua, herbicide resistance, integrated weed management, reduced herbicide rates, sethoxydim, tralkoxydim

\begin{abstract}
Model simulations predict that lowering herbicide efficacy by reducing the application rate would slow the rate of enrichment of herbicide-resistant individuals in a weed population, but the resulting increase in density of susceptible plants would reduce crop yield and increase the weed seedbank. A study was conducted at three sites in Saskatchewan from 1997 to 2000 to examine the implication of reduced rates of Group 1 herbicides in a 4-year crop rotation, in conjunction with variable crop seeding rates, on the enrichment of resistant wild oat in a mixed (resistant and susceptible) population. Main plot treatments were crop (barley, canola, field pea, spring wheat), subplot treatments were crop seeding rate (recommended and high), and sub-subplot treatments were Group 1 herbicide rate $(0,0.33,0.67$, and 1.0 times the recommended rate). Herbicide rate frequently interacted with seeding rate in affecting wild oat seedling density, seed return, the viable fraction of the weed seedbank, and crop seed yield. As simulation models predict, reduced herbicide efficacy decreased the proportion of resistant individuals in the population. The high crop seeding rate compensated for a one-third reduction in herbicide rate by limiting total wild oat seed return and by reducing the number of resistant seedlings recruited from the seedbank. In a diverse cropping system, the level of resistance in the seedbank can be reduced without increasing the total (resistant plus susceptible) seedbank population by manipulating agronomic practices to increase crop competitiveness against wild oat when Group 1 herbicide rates are reduced to a maximum of two-thirds of that recommended.
\end{abstract}

\section{Introduction}

Wild oat is the worst annual grass weed in the prairies, and the increasing incidence of herbicide resistance in this species is compounding the difficulty of its management. Model simulations predict that reduced rates that lower efficacy will slow the rate of enrichment of herbicideresistant individuals in a population, but the resulting increase in density of susceptible plants will reduce crop yield and increase the weed seedbank (Gorddard et al. 1996; Morrison and Friesen 1996). These simulations have used input parameters based on field data, but the outputs have not been validated with field data. In addition, the effect of reduced rates in combination with cultural weed management practices on resistant weed population dynamics is not known. Accordingly, the objective of this study was to determine the implication of reduced rates of Group 1 herbicides in conjunction with cultural weed management practices on the enrichment of resistance in wild oat. 


\section{Materials and Methods}

The 4-year experiment was conducted from 1997 to 2000 at three sites: Rosetown (Mixed Grassland ecoregion), Watrous (Aspen Parkland), and North Battleford, SK (Boreal Transition). The sites, which were located on pasture land, were tilled in 1996; observations confirmed the absence of a wild oat seedbank at each site. The experiment was arranged in a split-split plot design with four replications. Main plot treatments were crop: barley 'AC Oxbow', canola 'AC Excel', field pea 'Grande', and spring wheat 'AC Barrie'. Crops were grown in a 4-year rotation under minimum tillage: pea-wheat-canola-barley, with all phases present each year. Subplot treatments were crop seeding rate: recommended and 1.3-(pea) or 1.5-times higher (canola, barley, wheat) (Table 1). Crop rows were $20 \mathrm{~cm}$ apart. Sub-subplot $(2.5 \mathrm{X} 10 \mathrm{~m})$ treatments were Group 1 herbicide rates of $0.33,0.67$, and 1.0 times the recommended rate and a control.

In spring of 1997, susceptible wild oat was broadcast at 200 seeds $\mathrm{m}^{-2}$. Seedlings of the resistant biotype, UM1, were later transplanted into plots at a rate of $2 \%$ of the susceptible population and marked with a colored ring. This resistant biotype has been well characterized; resistance was attributed to an altered target site, ACCase, conferred by a single, semidominant, nuclear gene (Heap et al. 1993; Murray et al. 1995; Shukla et al. 1997). Crop plant density was measured 3 weeks after emergence and wild oat density at 3 weeks after herbicide application in four 0.25 $\mathrm{m}^{2}$ quadrats per plot. Weed and crop biomass and seed yield were measured at plant maturity. Wild oat seeds harvested in the final year (2000) and seedlings recruited from the seedbank at the end of the experiment ( 25 soil cores per plot, with bulked soil subsequently placed in trays) were tested for Group 1 resistance using established protocols.

Data were subjected to ANOVA. Rate-response data were analyzed using nonlinear (loglogistic), curvilinear (quadratic), or linear regression. Curves were compared using the lack-of-fit $F$ test $(P=0.05)$ (Seefeldt et al. 1995).

\section{Results and Discussion}

Increasing the seeding rate of canola, barley, and wheat by $50 \%$ resulted in about $40 \%$ higher plant densities of each crop for 10 of 12 site-years; the high seeding rate of pea resulted in 30\% greater plant stands in 9 of 12 site-years (data not shown). Wild oat seedling density responded to increasing herbicide rates differently between crop seeding rate treatments in barley and pea, but not in wheat or canola (Fig. 1; LN=natural log).

Table 1. Crop Seeding Rate and Herbicide Rate Treatments.

\begin{tabular}{|c|c|c|c|c|c|c|}
\hline \multirow[b]{2}{*}{ Crop } & \multicolumn{2}{|c|}{ Seeding rate $\left(\mathrm{kg} \mathrm{ha}^{-1}\right)$} & \multicolumn{4}{|c|}{ Rate (proportion of recommended) } \\
\hline & Recommended & High & Herbicide & 0.33 & 0.67 & 1.0 \\
\hline Canola & 7 & 10 & Sethoxydim & 60 & 120 & 180 \\
\hline Barley & 67 & 100 & Tralkoxydim & 67 & 133 & 200 \\
\hline Pea & 207 & 270 & Sethoxydim & 60 & 120 & 180 \\
\hline Wheat & 90 & 135 & Tralkoxydim & 67 & 133 & 200 \\
\hline
\end{tabular}






Figure 1. Response of wild oat seedling density to the recommended ( $\bullet$ ) and high seeding rate (-๑-) at increasing rates of tralkoxydim and sethoxydim (averaged across site-years).

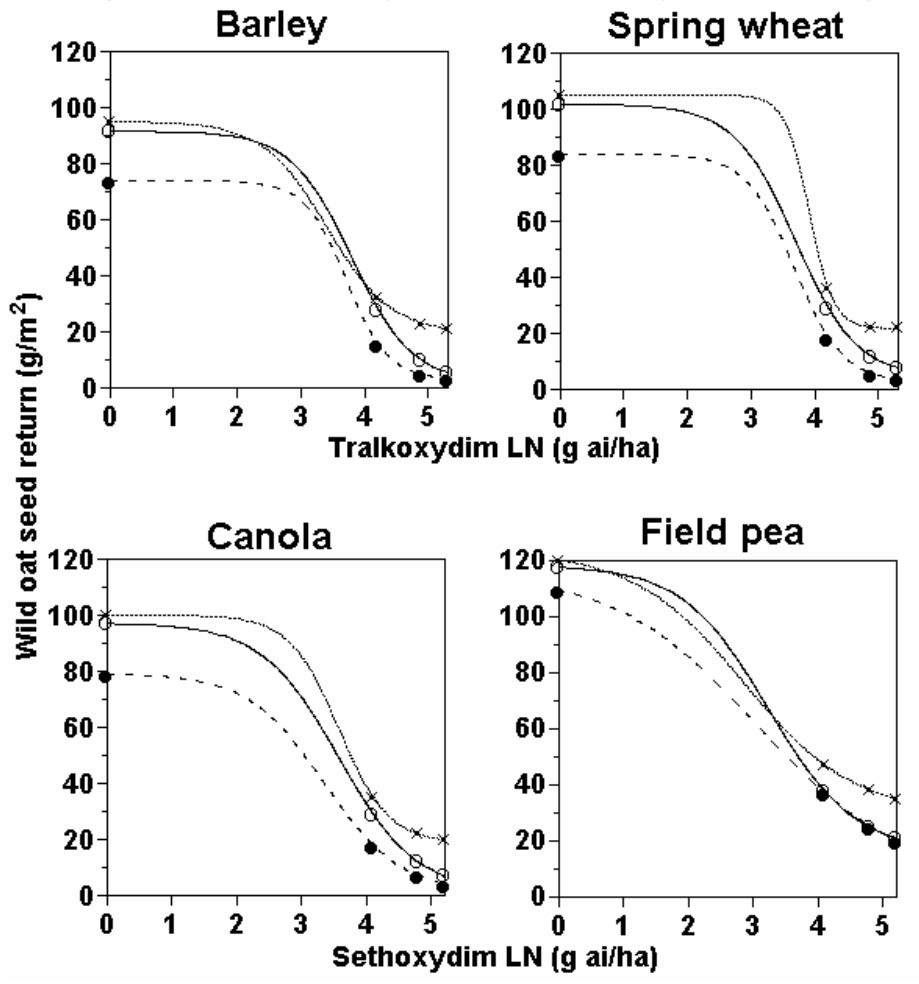

Figure 2. Response of wild oat seed return to the recommended ( $\bullet$ ) and high seeding rate (-๑-) at increasing rates of tralkoxydim and sethoxydim (averaged across sites, 1997-1999). The response in 2000 (...x...) did not differ between crop seeding rate treatments. 
Herbicide efficacy was reduced at all sites in 2000 compared with that in the previous 3 years (data not shown). Differences in weed densities between seeding rates were greatest in the untreated control plots (10-15\%); lowest densities were in barley, the most competitive crop.

Wild oat seed return differed between seeding rates in barley, wheat, and canola (Fig. 2). Seed return at two-thirds of the recommended herbicide rate and the high seeding rate was similar or lower than that at the full herbicide rate and the recommended seeding rate. Thus, enhanced cultural weed control compensated for reduced herbicide rates only in relatively competitive crops. Seed return, like density, was higher in 2000 than the previous 3 years.

Seed yield response of barley, wheat, and canola differed between seeding rates, but not pea (Fig. 3).

The percentage of Group 1-resistant individuals in wild oat seeds harvested in the final year increased linearly with increasing herbicide rates (Fig. 4). In simulation models, the percentage of resistant individuals in a population is directly proportional to selection pressure, estimated by weed seed yield reduction. Reduced efficacy (density, seed return) in 2000 was thus attributed to resistance in an increased proportion of the population.

The total seedbank (susceptible plus resistant) response to increasing herbicide rates differed between seeding rates, but not among crops (Fig. 5-Left). The seedbank densities of resistant seedlings in plots treated with herbicides were lower for the high vs. recommended seeding rate

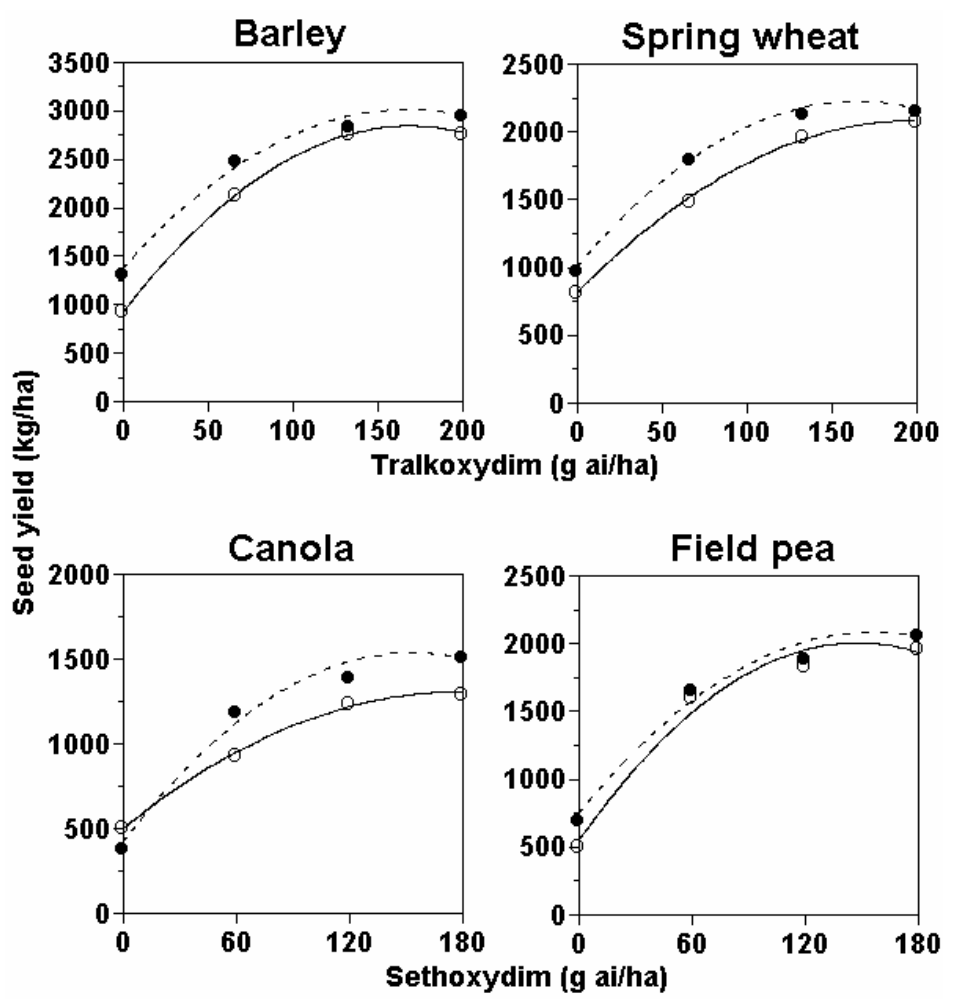

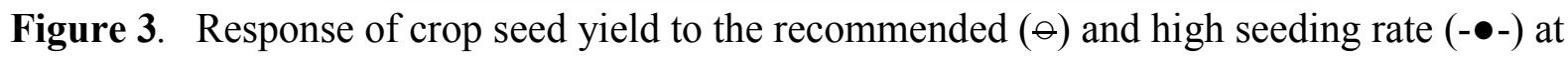
increasing rates of tralkoxydim and sethoxydim (averaged across site-years). 


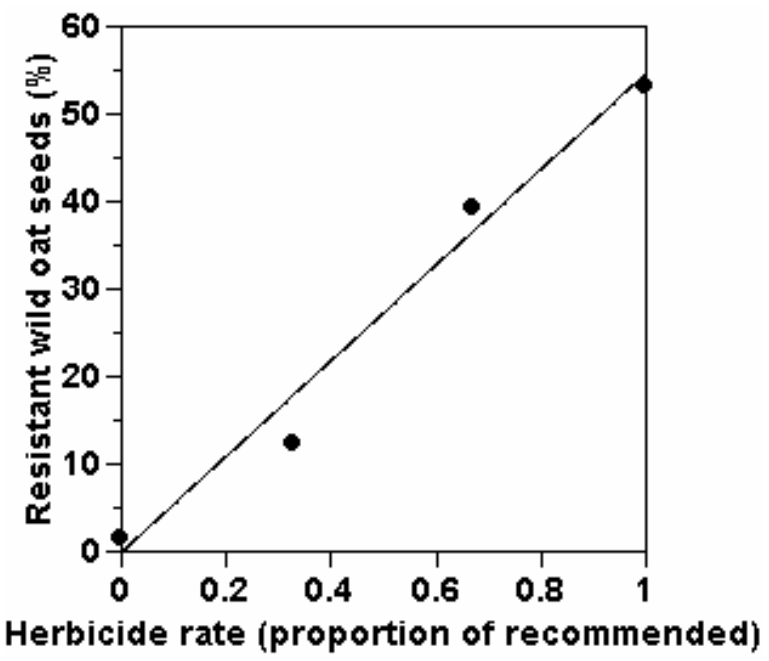

Figure 4. The percentage of Group 1-resistant wild oat individuals in seeds harvested in the final year of the experiment (averaged across crops, seeding rates, and sites) after 4 years of herbicide application. Equation is $y=-0.13+55.0 x ; R^{2}=0.98$.


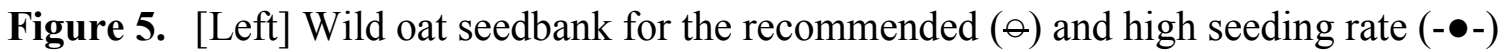
treatments at the conclusion of the experiment, as a function of Group 1 herbicide rate; [Right] Group 1-resistant wild oat seedlings from the seedbank at the conclusion of the experiment for the recommended $(\ominus)$ and high seeding rate $(-\bullet-)$ treatments at reduced and recommended herbicide rates.

(Fig. 5-Right). Resistant seedling density in plots seeded at the high rate and treated with twothirds of the recommended herbicide rate were lower than that in plots seeded at the recommended rate and where the full-recommended rate of herbicide had been applied.

The results of this field study agree with simulation model predictions that reduced rates with less efficacy decrease the rate of enrichment of resistance in weed populations. The high seeding 
rate in cereals and canola was able to compensate for a one-third reduction in herbicide rate in limiting total wild oat seed return and also in reducing the number of resistant seedlings recruited from the seed bank. Thus, in a diverse crop rotation where agronomic practices are employed to enhance the weed competitiveness of the crop and herbicide efficacy is enhanced by proper application timing relative to weed growth staging, farmers may be able to reduce Group 1 rates in relatively competitive crops. In that management system, we have shown that the level of resistance in the seedbank can be reduced without increasing the total (resistant plus susceptible) seedbank by lowering herbicide rates to a maximum of two-thirds of that recommended. Moreover, yields of cereal and oilseed crops are not adversely affected. For wheat and barley, the higher seed costs would be substantially offset by lower herbicide costs, resulting in input savings of $\$ 5$ to $\$ 8 /$ ha. However, the additional cost of canola seed would be greater than the savings in herbicide costs. Nevertheless, farmers must consider the direct and indirect short- and long-term costs of herbicide resistance, which are usually highest in grass weed species.

\section{Acknowledgments}

This study was supported by the Western Grains Research Foundation and the Matching Investment Initiative of AAFC. Land was provided by PFRA. We thank Scott Shirriff, Christopher Lozinski, and the rest of the AAFC staff for their technical expertise.

Gorddard, R. J., Pannell, D. J. and Hertzler, G. 1996. Economic evaluation of strategies for management of herbicide resistance. Agric. Syst. 51:281-298.

Heap, I. M., Murray, B. G., Loeppky, H. A. and Morrison, I. N. 1993. Resistance to aryloxyphenoxypropionate and cyclohexanedione herbicides in wild oat (Avena fatua). Weed Sci. 41:232-238.

Morrison, I. N. and Friesen, L. F. 1996. Herbicide resistant weeds: mutation, selection, misconception. Proc. $2^{\text {nd }}$ Int. Weed Control Congress, Copenhagen, Denmark. pp. 1-9.

Murray, B. G., Morrison, I. N. and Brûlé-Babel, A. L. 1995. Inheritance of acetyl-CoA carboxylase inhibitor resistance in wild oat (Avena fatua). Weed Sci. 43:233-238.

Seefeldt, S. S., Jensen, J. E. and Fuerst, E. P. 1995. Log-logistic analysis of herbicide dose response relationships. Weed Technol. 9:218-227.

Shukla, A., Dupont, S. and Devine, M. D. 1997. Resistance to ACCase-inhibitor herbicides in wild oat: evidence for target site-based resistance in two biotypes from Canada. Pestic. Biochem. Physiol. 57:147-155. 